Vol. 21 (2017), pp. 27-43

ISSNe: 2530-6324 || ISSN: 1138-039X

DOI: https://doi.org/10.17979/afdudc.2017.21.0.3270

\title{
LA PERVERSIDAD DE LAS TASAS JUDICIALES EN EL SISTEMA CONSTITUCIONAL
}

\author{
JORGE COUSO FERNÁNDEZ-GETINO \\ Abogado \\ CCS Abogados y Asesores de Empresa
}

\begin{abstract}
Resumen: Las tasas judiciales han constituido una figura tributaria que ha contado con el rechazo de todos los operadores jurídicos por su carácter limitador del derecho fundamental a la tutela judicial efectiva. El Tribunal Constitucional ha aplicado parches jurisprudenciales sobre este tributo suprimiendo paulatinamente gran parte del gravamen para solventar las graves deficiencias constitucionales y tributarias del legislador en su regulación. Su justificación constitucional encontraba en la justicia gratuita su respaldo legislativo pero se ha demostrado que no se ha satisfecho este fin legítimo que exige la jurisprudencia. En cualquier caso, un tributo que además del intrínseco carácter tributario es dotado de efectos procesales estaba condenado a su eliminación, como así ha sido, pese al insuficiente y paulatino proceso de adaptación constitucional.
\end{abstract}

Palabras clave: Tasas, derecho a la tutela judicial efectiva, consecuencias procesales, vías de recurso, capacidad económica, equivalencia y justicia gratuita.

Abstract: The Court Fees has constituted a tax figure that has been rejected by all law professionals because of the limiter nature of judicial protection right. Constitutional Court has implemented jurisprudential patches about this tribute deleting gradually a large part of fee to solve the severe constitutionals and tax deficiencies. Its constitutional justification had in legal aid free the regulatory support. However it has been proved that the legitimate aim has not fulfilled. In any case, one tribute with the tax nature and also procedural effects was condemned to its elimination, like in this way has been despite of the insufficient and gradually constitutional adaptation process.

Keywords: Fees, judicial protection right, procedural effects, appeal procedures, purchasing capacity, equivalence and legal aid free 
SUMARIO: I.INTRODUCCIÓN II. EVOLUCIÓN HISTÓRICA III.DOCTRINA JURISPRUDENCIAL DEL DERECHO A LA TUTELA JUDICIAL EFECTIVA IV. CONSECUENCIAS PROCESALES DEL IMPAGO DE LA TASA V. EL ESTRECHAMIENTO DE LAS VÍAS DE RECURSO VI. ANÁLISIS TRIBUTARIO: PRINCIPIOS DE CAPACIDAD ECONÓMICA Y EQUIVALENCIA VII. FINALIDAD RECAUDATORIA VIII.LA JUSTIFICACIÓN DE LA JUSTICIA GRATUITA IX. AFECTACIÓN A LAS PERSONAS JURÍDICAS X. COMENTARIO SOBRE LA STC $140 / 2016$

\section{I.INTRODUCCIÓN}

El concepto aristotélico de justicia distributiva implicaba la contribución de los ciudadanos en las cargas públicas en la misma proporción en que son acreedores de ese gasto público, sentando el precedente del denominado principio de beneficio en la tributación. Más tarde, Santo Tomás de Aquino influido por la visión del concepto de justicia distributiva de Aristóteles rompe con el pensamiento católico clásico sobre que la legitimación del pago de los impuestos se debía a que los gobernantes ejercían un poder emanado de Dios y la obligación de pagarlos constituía un deber moral, tanto si eran justos como si no.

Pues bien, Santo Tomás revistió de carácter ético las cargas impositivas porque consideraba que sólo los impuestos justos producen el deber moral de pagarlos y estableció las bases éticas que todo gravamen debe poseer:

Causa final: Un impuesto sólo es lícito cuando se dedica al bien común y está justificado por los beneficios que producen para la comunidad.

Causa eficiente: El impuesto debe ser aprobado por la autoridad competente con las debidas garantías

Causa material: El impuesto debe gravar a quien tenga la capacidad económica suficiente para hacer frente a su pago.

Causa formal: El impuesto debe guardar la debida proporcionalidad entre la cuantía y la capacidad económica del obligado tributario.

Respecto a las tasas judiciales, es objeto del presente artículo acreditar que no cumple con las bases éticas que la filosofía escolástica y concretamente Santo Tomás de Aquino ha desarrollado y que inspiran los preceptos de la Constitución española como el art 31.1 que ha sido vaciado de contenido por el propio Tribunal Constitucional en beneficio del afán recaudatorio del Estado carente de ética impositiva.

Este escenario de implantación de un tributo en la administración de justicia ya ocurrió en la Inglaterra de finales del siglo XVIII y la malignidad de las tasas judiciales ya fue 
denunciada por el padre del utilitarismo, Jeremy Bentham, en su libro "Una protesta contra las tasas judiciales" en la que advertía de su efecto obstructivo en el acceso a la justicia que además coincidía en tiempos de crisis económica como en el caso español.

BENTHAM, J. (1793) explica con estas palabras la lesividad de este tributo: "Justicia es la seguridad que la ley nos procura, o profesa procurarnos, para todo aquello que valoramos o debemos valorar, como es la propiedad, la libertad, el honor y la vida. Justicia es esa posesión que vale lo que todas las demás juntas, ya que las incluye a todas. Una denegación de justicia es la quintaesencia misma del daño, la suma y la sustancia de toda suerte de daños; no es robo solamente, ni esclavitud solamente, ni injuria solamente, ni homicidio solamente: es robo, esclavitud, injuria y homicidio todo en uno".

La historia se repitió y la aflicción de la tasa judicial al litigante resurgió con fuerza con la Ley 10/2012. No es baladí en el contexto actual afirmar, a tenor de los hechos que se expondrán en este artículo, que la injerencia de la Hacienda Pública en la Justicia tenga una justificación estrictamente recaudatoria y que ya BENTHAM, J. (1793) denunció cuando aseveró lo siguiente: "para una imaginación libre de prejuicios, la alianza entre Justicia y Hacienda... compone una estampa demasiado pegada a la verdad para considerarla una fábula".

\section{EVOLUCIÓN HISTÓRICA}

Las tasas judiciales no son un fenómeno extraño en nuestra administración de justicia, tienen una larga historia. En España se implementaron con el Decreto 1035/1959 de convalidación y regulación de la exacción de la tasa judicial, de 18 de junio, modificado por otro Decreto de 5 de noviembre de 1959.

Estaban obligadas al pago de las tasas judiciales "las personas naturales o jurídicas que promuevan la actuación de los Tribunales y Juzgados o sean parte en el proceso, salvo los casos de no sujeción o exención determinados por los preceptos vigentes" (Art. $3^{\circ}$ ). Por ello, el acceso a los tribunales estaba gravado con una tasa que tenía los mismos sujetos pasivos que tenía ley 10/2012 a su entrada en vigor, lo cual refleja el claro retorno a una técnica recaudatoria que ya existía en la época preconstitucional y que incluso puede considerarse menos restrictiva en el acceso a la justicia de los ciudadanos.

Uno de los aspectos que permite considerar la ley 10/2012 más restrictiva que el Decreto de 1959 es que esta norma es estrictamente tributaria y no tiene ninguna consecuencia procesal. El secretario judicial liquidaba la tasa por triplicado, contra la que cabían los recursos pertinentes ante el Juzgado o Tribunal, pero la falta de pago no paralizaba el trámite del procedimiento, ni suponía la inadmisión de la demanda o recurso, únicamente facultaba al tribunal para instar la vía de apremio. Una de las novedades que incorporaba las nuevas tasas judiciales es que la norma alcanza un doble carácter tributario y procesal que faculta al secretario judicial a paralizar el procedimiento, como veremos más adelante. 
Con la Ley 25/1986 de 24 de diciembre se estableció la medida de suprimir las tasas judiciales del régimen anterior al considerarlas incompatibles con el Derecho Fundamental del art.24 de la Constitución de 1978 que dispone que "Todas las personas tienen derecho a obtener la tutela efectiva de los jueces y tribunales en el ejercicio de sus derechos e intereses legitimos, sin que, en ningún caso, pueda producirse indefensión".

En la Exposición de Motivos de esta Ley el legislador fundamentaba la supresión de las tasas amparándose en el artículo 1 de la $\mathrm{CE}$ que propugna como valores superiores del ordenamiento jurídico la libertad, la justicia, la igualdad y el pluralismo político. También se amparaba en el párrafo 2 del artículo 9, que obliga a los poderes públicos a promover las condiciones para que la libertad y la igualdad sean reales y efectivas, así como remover los obstáculos que impidan o dificulten su plenitud.

Esta norma vincula los valores constitucionales en la Administración de Justicia como una manifestación del derecho a obtener la tutela judicial efectiva de los derechos e intereses legítimos y para que el mandamiento constitucional de que la libertad y la igualdad sean reales y efectivas se cumpla, todos los ciudadanos, sin excepción, deben obtener justicia "cualquiera que sea su situación económica o su posición social". Para la consecución de este objetivo dicha Ley anunciaba que, además de la supresión de las tasas, se reforzaría el beneficio de la asistencia jurídica gratuita dotándola de un presupuesto mayor y extendiéndolo a más estratos sociales en aras de que la Justicia fuese accesible a toda la sociedad.

Por otro lado, la ordenación de las tasas judiciales era incompatible con algunos principios tributarios y causaba notables distorsiones en el funcionamiento de la Administración de Justicia. En lo relativo a la gestión tributaria, encomendada al Secretario Judicial, se había demostrado poco eficiente y apartaba a este funcionario de las importantes funciones procesales y de gestión de la Oficina Judicial que está llamado a desempeñar.

Posteriormente, con la Ley 53/2002 de 30 diciembre, de medidas fiscales, administrativas y del orden social se introdujo en su art.35 la mal denominada "tasa por el ejercicio de la potestad jurisdiccional", ya que si nos atenemos a una comprensión literal el ejercicio de la potestad jurisdiccional corresponde en exclusiva a los Juzgados y Tribunales, como dispone el art.117.3 CE, por lo tanto se estaría gravando como sujetos pasivos de la tasas a los Juzgados y Tribunales que son los que ejercen dicha potestad y no a los justiciables, en todo caso debería denominarse "tasa por promover el ejercicio de la potestad jurisdiccional"1.

Dejando a un lado la semántica jurídica, la Ley 53/2002 supuso un resurgimiento parcial de las tasas judiciales, ya que solo gravaban a las personas jurídicas y únicamente a aquellas que tuvieran durante el periodo impositivo inmediato anterior un importe neto de la cifra de negocios superior a 6 millones de euros, cuantía que posteriormente fue ampliada a 8 millones de euros y, por último, después del Decreto-Ley 13/2010, de 3 de diciembre, a 10 millones. De esta forma, las entidades sin ánimo de lucro y las consideradas de reducida dimensión según la legislación del impuesto de sociedades quedaban exentas.

${ }^{1}$ RODRIGUEZ CARBAJO, José Ramón. ” Las tasas judiciales: retorno a 1959”, cit.p.3 
Finalmente, con la Ley 10/2012, el ámbito subjetivo la tasa no solo se extendió a las entidades mercantiles con un elevado nivel de facturación como hacía la Ley 53/2002, sino que incluye a la mayoría de personas físicas y jurídicas hasta la supresión de las primeras a través del Real Decreto-Ley 1/2015 de 27 de febrero.

\section{DOCTRINA JURISPRUDENCIAL DEL DERECHO A LA TUTELA JUDICIAL EFECTIVA}

El derecho de la tutela judicial efectiva tiene, en palabras del TC, un contenido complejo y se proyecta en cuatro vertientes:

-El derecho de acceso a los tribunales

-El derecho a obtener una sentencia fundada en derecho

-El derecho a la efectividad de las resoluciones judiciales

-El derecho al recurso legalmente previsto ${ }^{2}$

En concreto, este gravamen afecta fundamentalmente al ejercicio del derecho de acceso a los tribunales y también al derecho a los recursos. En este epígrafe nos centraremos en el primero:

El derecho de acceso a los órganos judiciales forma parte del contenido esencial del derecho a la tutela judicial efectiva en la medida de que, como es lógico, no es posible ejercitar el resto de derechos que integran el derecho fundamental del art.24.1CE si antes el justiciable que ha sufrido una lesión de un derecho subjetivo o de un interés legítimo no accede a los órganos judiciales para plantear ante ellos la correspondiente pretensión procesal.

El Tribunal Constitucional ha definido el derecho de acceso a la Jurisdicción como el "derecho a ser parte en un proceso para promover la actividad jurisdiccional que desemboque en una decisión judicial sobre las pretensiones deducidas" (SSTC 251/2007, de 17 de diciembre, 26/2008 de 11 de febrero). Lo que quiere decir el TC es que este derecho es el eje central de la tutela judicial efectiva porque constituye la garantía de que los demás derechos puedan ejercitarse, ya que sin promover y acceder a un proceso judicial es imposible obtener una resolución fundada en derecho $\mathrm{y}$ congruente por motivos cronológicos y de orden.

Por ello, este derecho se erige como el núcleo del derecho a la tutela judicial efectiva, imprescindible en un Estado democrático y de Derecho como el español. De ahí que muchos organismos internacionales y europeos como el Consejo de Europa consideren la accesibilidad a la justicia como un "termómetro" para medir la robustez de un sistema de derechos fundamentales y la calidad democrática de un país, ya que si los ciudadanos no acceden a los tribunales para que se les reconozcan sus derechos todo el catálogo de derechos fundamentales y libertades públicas que consagra la $\mathrm{CE}$ quedaría en papel

\footnotetext{
${ }^{2}$ PICÓ Y JUNOY, Joan. Las garantías constitucionales del proceso, Bosch Procesal, Barcelona 2012, p.57
} 
mojado. Así lo dispuso el TEDH cuando en la STEDH de 21 de febrero de 1975, Golder contra Reino Unido, introdujo el derecho de acceso como uno de los componentes del derecho a un juicio justo que consagra el art.6 del Convenio de Roma y también la Unión Europea en el art.47 de la Carta de los Derechos Fundamentales.

Sin embargo, pese a todo el reconocimiento internacional como garante y componente nuclear de la efectividad del sistema de derechos fundamentales, no estamos ante un derecho absoluto sino que existen limitaciones que supeditan su ejercicio y dispensación a la concurrencia de una serie de presupuestos y requisitos que en cada caso establezca el legislador, ya que el art. $24 \mathrm{CE}$ le confiere un carácter de derecho prestacional de configuración legal cuyo alcance y contenido será determinado por normas legales.

De este modo, el TC ha establecido límites al legislador para regular los presupuestos y requisitos del acceso a la jurisdicción concluyendo que éste "no puede, dado el carácter de derecho fundamental que tiene, fijar obstáculos o trabas arbitrarias o caprichos que lo dificulten, sin que tal dificultad esté en modo alguno justificada por el servicio a un fin constitucionalmente lícito." (SSTC 228/2006, de 17 de Julio, 325/2006, de 14 de diciembre).

De esta forma, el obstáculo legal del acceso a los tribunales para ser legítimo desde el punto de vista constitucional, "deberá obedecer a razonables finalidades de protección de bienes e intereses constitucionalmente protegidos y deberá guardar una notoria proporcionalidad con la carga de diligencia exigible a los justiciables" (STC 13/2008, de 31 de enero).

Pues bien, dada la flexibilidad de la tasa en su configuración lo que se demanda es una mayor mesura en el alcance de su intensidad y eso sólo es posible si respeta las dos exigencias que establece el TC:

1) Que la tasa obedezca a un fin legítimo.

2) Que se guarde una relación de proporcionalidad entre el fin perseguido y el medio que lleve a considerar la tasa como una restricción razonable del derecho de acceso a los Tribunales.

\section{CONSECUENCIAS PROCESALES DEL IMPAGO DE LA TASA}

La clave sobre la justificación de la tasa judicial como limitación en el acceso a la justicia reside en el examen de proporcionalidad a fin de establecer si los objetivos a los que sirve dicho tributo son acordes con su configuración legal, es decir, con el contenido de la norma que lo regula.

Que el pago de la tasa constituya un requisito de procedibilidad en el que su cumplimiento deviene una condición sine qua non para obtener la tutela judicial efectiva, considero que es un efecto que provoca el cierre de la jurisdicción de manera desproporcionada, ya que tendría perfectamente encaje que se produjese el devengo del tributo al término del pleito, es decir, en el momento en que se dicta sentencia en lugar 
de la interposición de la acción como establece ley 10/2012 y de esta forma respetar el principio proactione. Esta posibilidad ha sido contemplada por el TEDH en el caso Stankov contra Bulgaria, en el cual legitima el sistema de tasas judiciales en el que se devengan éstas al final del proceso.

En este sentido, sería más lógico aplicar la "tributarización" de la tasa judicial, que consiste en trasladar a la administración tributaria la gestión del cobro de la tasa para que impulsase la exacción a través de la liquidación de oficio o por la vía ejecutiva de apremio y mientras la tramitación del proceso seguiría su curso desprovisto de la repercusión procesal de verse privado del acceso al mismo, lo cual constituiría un agravio demasiado severo y desproporcionado para el justiciable.

Sin embargo, el TC se ha desmarcado de esta doctrina en la STC 20/2012 de 6 de febrero y avala la postura del legislador de garantizar la recaudación eficaz de la tasa y el cumplimiento del pago que justifica este tratamiento procesal tan severo.

Por lo tanto, sorprende este criterio del Tribunal Constitucional cuando respecto a otra figura tributaria en la sentencia 141/1988, de 12 de Julio, declaró la inconstitucionalidad del art.57.1 de la Ley de Impuestos de Transmisiones Patrimoniales y Actos Jurídicos Documentados de 1980 porque impedía que surtieran efectos procesales los documentos respecto de los que no se había girado el tributo. Este efecto obstativo se consideró que conculcaba el derecho de acceso a la justicia por su desproporcionalidad.

\section{EL ESTRECHAMIENTO DE LAS VÍAS DE RECURSO}

Dentro del derecho a la tutela judicial efectiva se encuentra implícitamente inserto el derecho de acceso al recurso que comporta "el derecho a que los interesados puedan utilizar aquellos medios de impugnación que el ordenamiento disponga "(STC 253/2007 de 17 de diciembre). Este derecho es de absoluta configuración legal en los procesos no penales, es decir sin el límite de no afectar al contenido esencial del mismo, "pues mientras que en el derecho a poder dirigirse a un juez en primera instancia para hacer valer un derecho tiene naturaleza constitucional por nacer directamente de la Ley suprema, en cambio, el que se revise la respuesta judicial por la vía del recurso es un derecho cuya configuración se defiere a las leyes" (STC 241/2007 de 10 de diciembre). En cambio, en los procesos penales el contenido esencial del derecho sí deriva directamente de la Constitución y existe el mandato ineludible de que el legislador mantenga la concurrencia de un recurso que permita someter ante un tribunal superior toda condena penal impuesta en primera instancia.

De esta forma, el legislador ordinario puede hacer y deshacer a su antojo lo que considere en relación con el derecho de acceso a los recursos en los procesos no penales, ya que el alcance del mismo y su contenido esencial son ciertamente pobres, endebles, vacíos o escasos en comparación con el derecho de acceso a la jurisdicción. La protección constitucional de este derecho es tan paupérrima que si el legislador decidiese eliminar íntegramente la existencia de todos los medios de impugnación en los procesos no penales podría hacerlo sin vulnerar la Constitución, ya que es 
“imaginable, posible y real la eventualidad de que no existan" (STC 241/2007 de 17 de diciembre).

El TC ya utilizó este argumentario al pronunciarse sobre el efecto de las tasas judiciales respecto al recurso de apelación civil en la Ley 53/2002, concretamente se dijo que: "Con mayor razón debemos alcanzar la misma conclusión cuando lo que se subordina al abono de la tasa judicial no es la admisión de una demanda, protegida por el derecho de acceso a la justicia, sino la admisión de un recurso establecido por la ley, como es el recurso de apelación civil, pues el derecho de acceso a los recursos recibe un menor grado de protección desde el punto de vista del derecho fundamental a la tutela judicial efectiva"(STC 79/2012 de 17 de abril).

Esta degradación tan acusada del derecho a las vías de recurso respecto al derecho de acceso al proceso es una tendencia que, a mi juicio, resulta preocupante en el sentido de que es un derecho ya de por sí cercenado y que con las tasas esto se intensifica todavía más, ya que se pierde una parte de tutela judicial importante como es la que ejercen los tribunales superiores que con la elevada subida de las cuantías de las tasas en los recursos se instala un efecto disuasorio que llega a obstaculizar el acceso a los recursos $\mathrm{y}$ hace ver a los justiciables que la segunda instancia y la vía casacional son lujos reservados para quien pueda costearlos.

Me parece muy interesante la postura adoptada por el catedrático de Derecho Procesal y ex-letrado del TC, José Garberí Llobregat, sobre la ubicación constitucional del derecho de acceso a los recursos. Este procesalista sostiene que la incardinación constitucional del derecho a los recursos debería situarse en torno a el genérico derecho a un proceso con todas las garantías (art.24.2 CE) ${ }^{3}$, alegando que los medios de impugnación son una "garantía esencial del proceso" en el sentido de que son una garantía del acierto judicial en la resolución de las controversias, una garantía frente al arbitrio y el voluntarismo judicial y una garantía para el justiciable que ve en ellos un elemento que hace del proceso un elemento más fiable y seguro. De esta forma, no se daría esa absoluta subordinación de todo un derecho fundamental a la voluntad coyuntural y contingente del legislador de turno que exista en ese momento determinado.

Pero la tasa no constituye el único obstáculo económico para acceder a las vías de recurso, ya que los presupuestos procesales son muy estrictos para acceder a instancias superiores, buen ejemplo de ello es la cuantía máxima que ha de alcanzar el proceso para poder interponer un recurso, la conocida como summa graviminis, que ha sufrido aumentos como consecuencia de la Ley de agilización procesal de $30.000 €$ en el recurso de apelación y $600.000 €$ en el de casación, lo que supone un gran escollo para el justiciable que quiere que su asunto sea sometido a una nueva revisión judicial por parte de una instancia superior. Sin hablar de otros elementos obstaculizadores como el depósito para recurrir que establece la LOPJ en su Disposición Adicional Decimoquinta y las costas procesales en régimen de vencimiento objetivo.

Este estrechamiento tan intenso del acceso a las vías de recurso que se establece con el gravamen de la tasa judicial provoca que el resultado de un pleito con pretensiones legítimas pueda estar manchado por un error judicial y al verse impedido en su acceso a

\footnotetext{
${ }^{3}$ GARBERÍ LLOBREGAT, José. El derecho a la tutela judicial efectiva en la jurisprudencia del tribunal constitucional, Bosch, Barcelona 2008, p.138
} 
otra instancia quede privado de una resolución fundada en derecho y acertada. El error judicial es uno de los motivos que legitiman la existencia de los recursos, ya que el error en los órganos judiciales no es una rara avis.

\section{ANÁlISIS TRIBUTARIO: PRINCIPIOS DE CAPACIDAD ECONÓMICA Y EQUIVALENCIA}

El art.31.1 de nuestra Carta Magna establece que "todos contribuirán al sostenimiento de los gastos públicos de acuerdo con su capacidad económica mediante un sistema tributario justo inspirado en los principios de igualdad y progresividad que, en ningún caso, tendrá alcance confiscatorio". Por lo tanto, el principio de capacidad económica se consagra como un principio constitucional que ha de inspirar todo el sistema tributario.

Las tasas judiciales, pese a ser un tributo especial, forma parte del sistema tributario y está supeditada a los preceptos de la Ley de tasas y precios públicos. Esta norma establece en su art.8 que "en la fijación de las tasas se tendrá en cuenta, cuando lo permitan las características del tributo, la capacidad económica de las personas que deben satisfacerlas".

Pues bien, para ajustar la cuantía de la tasa a la capacidad económica de los justiciables hemos de atenernos, en primer lugar, a indicadores económicos en abstracto que reflejen la capacidad económica de un ciudadano medio.

El TEDH para enjuiciar la proporcionalidad de este tipo de tributos que gravan el acceso a la justicia ha utilizado el criterio del salario mínimo mensual que un trabajador percibe en un determinado país (SSTEDH de 26 de Julio de 2005 Jedamski y Jedamska contra Polonia, 8 de junio de 2006 V.M c Bulgaria ,7 de Febrero de 2008, Beian contra Rumanía). Siguiendo este parámetro huelga decir que las cuantías de las tasas resultan desproporcionadas, ya que el salario mínimo es de 645,30 euros mensuales en España, superando montantes de otros países de nuestro entorno más próximo.

Además, es menester recordar lo manifestado por el Tribunal Constitucional en el fundamento jurídico décimo de la STC 20/2012, en el cual, el Alto Tribunal ya ofrecía las siguientes consideraciones relativas a la cuantía de la tasa y su eventual incidencia en el acceso a la jurisdicción: "Esta conclusión general sólo podría verse modificada si se mostrase que la cuantía de las tasas establecidas por la Ley 53/2002, de 30 de diciembre, son tan elevadas que impiden en la práctica el acceso a la jurisdicción o lo obstaculizan en un caso concreto en términos irrazonables, atendiendo a los criterios de la jurisprudencia expuestos en el fundamento jurídico 7”.

De este modo, es contrario a la normativa tributaria que se aplique indiscriminadamente una cuota fija y una cuota variable en función de la cuantía del procedimiento sin tener en cuenta en ningún momento la capacidad económica de quien pretende entablar un proceso judicial.

Si bien es cierto, que la doctrina del tribunal constitucional otorga un papel más predominante a este principio en los impuestos como el IRPF, también ha declarado que 
la capacidad económica debe ser el criterio informador y orientador de nuestro sistema tributario. Como pone de manifiesto en la STC 194/200 aseverando que "el tributo es una prestación patrimonial coactiva que se satisface, directa o indirectamente, a los entes públicos que por imperativo del art.31.1 CE sólo puede exigirse cuando existe capacidad económica y en función de la capacidad económica".

Por otro lado, el artículo 7 de la Ley de Tasas y Precios Públicos establece que "las tasas tenderán a cubrir el coste del servicio o de la actividad que constituya su hecho imponible", puesto que la ley exige que exista una correspondencia entre la cuota de la tasa y el coste del servicio cuando consagra en este precepto el llamado principio de equivalencia.

En consecuencia, para esclarecer esta equivalencia desempeñaba un papel importante la memoria económico-financiera que impone el art.20 de la Ley de Tasas y Precios Púbicos cuando dispone que "toda propuesta de establecimiento de una nueva tasa o de modificación específica de las cuantías de una preexistente deberá incluir, entre los antecedentes y estudios previos para su elaboración, una memoria económicofinanciera sobre el coste o valor del recurso o actividad de que se trate y sobre la justificación de la cuantía de la tasa propuesta. La falta de este requisito determinará la nulidad de pleno derecho de las disposiciones reglamentarias que determinen las cuantías de las tasas". Así como el art.22.2 de la Ley de organización, competencia y funcionamiento del Gobierno (Ley 50/1997, de 27 de noviembre) que establece que los anteproyectos de ley se iniciarán en el ministerio o ministerios competentes acompañando a éstos de la correspondiente memoria, los estudios o informes sobre la necesidad y oportunidad del mismo, un informe sobre el impacto por razón de género de las medidas que se establecen en el mismo, así como por una memoria económica que contenga la estimación del coste a que dará lugar y también la Ley de Economía Sostenible de 2011 en su artículo 4 (Ley 2/2011, de 4 de Marzo) en pos de mejorar la calidad de la regulación normativa, consagra los principios de necesidad, proporcionalidad, seguridad jurídica, transparencia, accesibilidad, simplicidad y eficacia.

Especial relevancia tiene respecto a la memoria económica el principio de transparencia, puesto que, aunque la memoria de impacto normativo de la Ley 10/2012 realiza una previsión de la recaudación que se espera obtener, adolece en cuanto no esclarece nada acerca del origen de la cuotas de las tasas judiciales, por qué tienen ese valor o cuánto cuesta el proceso judicial que grava el tributo. Este silencio fue denunciado por el Consejo de Estado en su informe cuando advirtió que "habría sido útil, además, que la memoria hubiera realizado un estudio del coste económico que los distintos tipos de procedimientos suponen para el Ministerio de Justicia como base para calcular de forma discriminada el porcentaje que en cada supuesto cubren las tasas establecida".4. Por lo tanto, queda patente aquí otra deficiencia técnica en la normativa de las tasas que es menester señalar y denunciar.

\section{VII.FINALIDAD RECAUDATORIA}

\footnotetext{
${ }^{4}$ https://www.boe.es/buscar/doc.php?id=CE-D-2012-774
} 
En la Exposición de Motivos de la Ley 10/2012 se hace referencia a que "con esta asunción por los ciudadanos que recurren a los tribunales de parte del coste que ello implica se pretende racionalizar el ejercicio de la potestad jurisdiccional, al mismo tiempo que la tasa aportará unos mayores recursos que permitirán una mejora en la financiación del sistema judicial y, en particular, de la asistencia jurídica gratuita”. Por lo tanto, la principal razón que motiva la existencia de las tasas judiciales es recaudar dinero para financiar la Administración de Justicia.

A pesar de la dimensión de la tasa, el total recaudado que asciende, según datos del Ministerio de Justicia, a 564,4 millones de euros, no permitiría cubrir todo el gasto público en justicia, que en los Presupuestos Generales del Estado de 2014 tuvo una dotación de 1.473 millones de euros (de los cuales el grueso corresponde al personal de la Administración de Justicia). De este modo, la tasa no soporta toda la carga del sustento de la financiación, pero sí que es un recurso financiero complementario para sufragar los gastos de la Justicia.

Una de las razones por las que se ha optado por la tasa judicial para gravar el hecho imponible de promover el ejercicio de la potestad jurisdiccional es la idea de que la financiación de la justicia recaiga sobre aquellos que la demandan y no sobre el conjunto de la ciudadanía. Partiendo este planteamiento desde una premisa, a mi modo de ver, errónea como es la consideración de que la Justicia solo sirve a un beneficio particular, olvidándose del beneficio general que reporta en la consecución de la paz social. Es decir, que los ciudadanos residan la solución de sus controversias y litigios a un poder público tiene como finalidad el mantenimiento de una convivencia ciudadana pacífica, ya que de esto modo no se ven obligados a recurrir a la autotutela o que lo comúnmente se conoce como "tomarse la justicia por su mano".

Por este motivo, considero que la financiación de la justicia debe realizarse a través de la vía impositiva ordinaria, ya que la colectividad se beneficia de que el sistema judicial solvente los conflictos de manera eficaz y pacífica. Por ejemplo, es conveniente que el control judicial de la Administración Pública sea efectivo y real para evitar la arbitrariedad de la administración en el ejercicio de la potestad sancionadora y también redunda en un beneficio general la construcción de jurisprudencia para uniformizar criterios judiciales.

Por lo tanto, es evidente que la existencia de seguridad jurídica y credibilidad en la potestad jurisdiccional cumple una función demasiado importante en un Estado Democrático, Social y de Derecho como para someterla al pago de una tasa como si fuera la tasa municipal de recogida de basuras y por eso debe financiarse vía impuestos, en lugar de la tasa que como concepto tributario está asociado al uso particular de un servicio público o a una actividad administrativa, lo que conlleva degradar la potestad jurisdiccional a la categoría de mera actividad prestacional como el transporte público, cuando de lo que se trata es de un derecho fundamental consagrado en el art.24 CE.

Sin embargo, la vía impositiva general sigue financiando la Administración de Justicia, ya que la implantación de las nuevas tasas judiciales no ha hecho desaparecer de los Presupuestos Generales del Estado las partidas destinadas a la Justicia, por lo que se ha 
optado por un modelo de financiación mixto que, en realidad, constituye un copago al sostener el ciudadano por una doble vía tributaria el mantenimiento del sistema judicial.

Este tipo de prácticas es posible en el statu quo actual porque el ordenamiento jurídico español carece de una economía constitucional fuerte que revista de mecanismos protectores frente a la tributarización de servicios por parte del sector público. La economía constitucional que propugna James M. Buchanan nace para garantizar el comportamiento interindividual reglado para la cooperación económica y se sirve del constitucionalismo como limitación gubernamental.

En efecto, una fuerte politización de la economía a consecuencia de una creciente intervención del Estado a través de artificios fiscales debe tener como respuesta a este fenómeno una estructura dada de reglas institucionales que no estén al servicio del Leviatán, sino que protejan contra la arbitrariedad de los poderes públicos a los individuos que interactúan como agentes económicos y sociales, ya que de la capacidad económica de estos mismos individuos dependerá el pago de los impuestos que contribuirán al sostenimiento del gasto público, incluido el realizado en la administración de justicia.

Y respecto al argumento del legislador en lo referente a "racionalizar el ejercicio de la potestad jurisdiccional" se desmonta cuando la LOPJ en su art 11.2 otorga a los jueces la facultad discrecional de rechazar todo tipo de peticiones formuladas con manifiesto abuso de derecho o que entrañen fraude legal o procesal en aras de preservar la buena fe procesal.

De hecho el art.247 de la Ley de Enjuiciamiento Civil establece que "los intervinientes en todo tipo de procesos deberán ajustarse en sus actuaciones a las reglas de la buena fe" extendiéndose por tanto a todas las jurisdicciones e incluso si "los Tribunales estimaren que alguna de las partes ha actuado conculcando las reglas de la buena fe procesal, podrán imponerle, en pieza separada, mediante acuerdo motivado, y respetando el principio de proporcionalidad, una multa que podrá oscilar de ciento ochenta a seis mil euros, sin que en ningún caso pueda superar la tercera parte de la cuantía del litigio". Esto significa que los mismos jueces pueden sancionar y castigar a los litigantes que abusan del proceso.

Por lo tanto, si los jueces son los encargados de salvaguardar la buena fe procesal y evitar que se abuse del proceso según el caso concreto, qué necesidad hay de imponer una tasa de afectación genérica que persiga este fin cuando por mandato legal se les encomiendan a los jueces que valoren cada asunto individualmente para que decidan si la pretensión del que pretende iniciar un procedimiento judicial no constituye un abuso de derecho y cumple con las reglas de la buena fe procesal.

La valoración circunstanciada que realice el juez para corregir la desproporcionalidad que puede ejercer la tasa en el justiciable es el mejor método para prevenir estos desequilibrios. Un trámite formal no debería de obstaculizar el acceso a la justicia, ya que como viene advirtiendo nuestro TC: "Los trámites formales no deben de ser exigencias cuyo cumplimiento presente siempre el mismo valor obstativo que operaría con independencia, en principio, de cuál sea el grado de inobservancia del requisito, su trascendencia práctica o las circunstancias concurrentes en el caso" (STC 36/1986, de 12 de Marzo). 
Pues bien, la bondad de la actuación judicial en la erradicación del abuso procesal es mayor que en la tasa judicial debido a que ésta actúa de manera indiscriminada afectando a todos los justiciables tengan razón o no en sus pretensiones. Como dijo con extraordinaria lucidez Jéremy Bentham en "Una protesta contra las tasas judiciales": "la lógica económica que puede llevar a desistir de entablar un pleito por el coste que ello entraña no sólo afecta al litigante perverso y querulante sino también al que actúa de buena fe y está asistido por la razón”. Por esta razón la configuración de la tasa ha de tener una orientación selectiva que se ajuste a cada caso concreto, de lo contrario se estaría castigando demasiado al conjunto de los justiciables que acudan a la justicia con causas legítimas produciendo un efecto punitivo que trasciende de la mera finalidad reflexiva que pretende el legislador en aras de conseguir un uso más racional de la justicia.

\section{LA JUSTIFICACIÓN DE LA JUSTICIA GRATUITA}

El artículo 11 de la Ley 10/2012 dispone que la recaudación obtenida con las tasas judiciales deberá destinarse al sostenimiento del sistema de justicia gratuita. Este mandato legal no tiene otra finalidad que la de servir como instrumento político para justificar la carestía de las tasas y así mitigar las voces críticas con el nuevo tributo.

Esto supone, si se me permite la metáfora, una medida que intenta curar el cáncer con el virus del ébola. Es decir, se pretende mejorar la justicia gratuita para los que no disponen, según la ley, de recursos para litigar mediante las tasas cercenando el acceso a la justicia de personas que no siendo beneficiarios de justicia gratuita no pueden asumir la cuantía de la tasa. Lo que promueve esta asociación entre la tasa y la justicia gratuita es el fraude, ya que muchos justiciables obligados al pago de la tasa con recursos para costearse un abogado y un procurador intentan eludirlo solicitando justicia gratuita a través de argucias de todo tipo, lo cual ya ha ocurriendo en la práctica.

Esta clase de fraudes también ocasionan una sobrecarga de trabajo para las comisiones de asistencia jurídica gratuita, por motivo del aumento de peticiones que surgen de la crisis económica y de la implantación de las tasas, que los 83 colegios de abogados no pueden asumir tras sufrir una disminución del gasto en financiación desde 2010 de este servicio público, pese al insuficiente aumento de un 2,3\% para el año 2015. Durante 2013, el importe destinado a este servicio público tan fundamental para los ciudadanos ha sido de 223 millones de euros, suponiendo un recorte con respecto a los 232 millones del año 2012. Esta cifra supone una reducción del 8,7\% con respecto a las inversiones en 2011, que alcanzaron el importe de 254,5 millones de euros. En 2010 (256 millones), la reducción fue del 4\% con respecto a 2009 (266 millones).

En conclusión, con este aumento de beneficiarios lo que se consigue es el colapso de la tramitación de los expedientes por parte de un sistema de justicia gratuita que venía funcionando de manera eficaz y satisfactoria (de hecho, el 90\% de los expedientes que tramitan son posteriormente ratificados por las Administraciones Públicas) al no contar con medios suficientes para afrontar la avalancha de justiciables que acudieron a la justicia gratuita con la actual regulación de las tasas. 
Pese a esta teórica vinculación finalista de la asistencia jurídica gratuita con la ley de tasas, se ha dejado traslucir que la verdadera vocación de la tasa es meramente recaudatoria y disuasoria.

Pues bien, las comunidades autónomas con competencias en Justicia como Madrid, La Rioja, Andalucía, Galicia y Navarra, entre otras, han tenido que reclamar el dinero obtenido de las tasas, puesto que no han recibido ni un sólo euro procedente de su recaudación, lo que denota la pésima regulación de este aspecto ya que no se establecen cauces formales para que el destino por imperativo legal que tienen las tasas judiciales sea la financiación del sistema de justicia gratuita, sino que se deja al arbitrio de los vaivenes que marca la agenda política del Ministro de Justicia. Otro déficit más de las denostadas tasas.

De esta forma, se ha incumplido el mandato legal de destinar esa recaudación al sostenimiento y mejora del sistema de justicia gratuita y con ello obviado el fin legítimo que perseguía la tasa judicial para su justificación constitucional, por lo que debemos recordar la doctrina del propio Tribunal Constitucional respecto a que no se puede fijar obstáculos o trabas arbitrarias o caprichos que dificulten, sin que tal dificultad esté en modo alguno justificada por el servicio a un fin constitucionalmente lícito. Y haciendo un juicio ex post, como la tasa judicial no ha respondido a ese fin carece de toda constitucionalidad que siga vigente incluso para personas jurídicas.

\section{AFECTACIÓN A LAS PERSONAS JURÍDICAS}

El legislador afirmaba en la Exposición de Motivos del Real Decreto 3/2013 que: "Dentro de la regulación de la determinación de la cuota tributaria de la tasa, las actuales circunstancias aconsejan la introducción de una escala específica para las personas naturales, con un tipo menor que el general, que se reservaría para las personas jurídicas". Esta novedad se sustentaba en la doctrina del TC sobre la ley de tasas de 2002, que como recuerdo sólo gravaba a las personas jurídicas, pero este planteamiento obvia que el radio de acción de esa regulación sólo alcanzaba a las entidades con una cifra de negocios de hasta 10 millones de euros partiendo de la premisa de que los que acuden a la justicia ostentando mayor caudal de recursos colaboren en el sostenimiento de la misma.

De esta manera, quedaban fuera de esta regulación las Pequeñas y Medianas Empresas (PYMES) y las entidades sin ánimo de lucro, las cuales están afectas actualmente al abono de las tasas sin exención ninguna en función de su capacidad económica contraviniendo el art.31 CE. Las personas jurídicas tienen reconocido el derecho al acceso a los tribunales por el Tribunal Constitucional, algo que el legislador parece olvidar, y que constituye una inconstitucionalidad absoluta atendiendo a la doctrina del TC (STC 117/1998 de 2 de junio).

En definitiva, las personas jurídicas no deberían de ser una excepción y también debería de aplicársele el principio de capacidad económica como establece el TEDH. Este tribunal considera que la capacidad económica de las empresas debe de ser el criterio a seguir para determinar si están en condiciones de abonar la tasa judicial y para enjuiciar 
la proporcionalidad de las tasas que afectan a las personas jurídicas utiliza los mismos parámetros que con las físicas (Teltronic CATV contra Polonia, STEDH de 10 de enero de 2006). El Tribunal de Estrasburgo también ha criticado la arbitrariedad de los sistemas de tasas judiciales que gravan a las empresas de forma indiscriminada partiendo de la lógica errónea de que por el hecho de ser empresas y tener afán de lucro ya poseen recursos económicos suficientes, como es el caso del estado armenio sobre el cual el TEDH sentenció que "una prohibición general de obtener la exención de las tasas judiciales genera por si misma un problema bajo el art.6.1" (STEDH de 20 diciembre de 2007, Paykar yev Haghtanak Ltd contra Armenia)

\section{COMENTARIO SOBRE LA STC 140/2016}

Respecto a la STC 140/2016, de 21 Julio de 2016, por un lado, establece que las tasas judiciales resultan desproporcionadas y pueden producir un efecto disuasorio a la hora de acudir a los Tribunales de Justicia en el ejercicio de su derecho fundamental a la tutela judicial efectiva. Sin embargo, el TC arguye que la tasa en sí misma no es inconstitucional, sino que la inconstitucionalidad recae en su cuantía. Esto no debe caer en saca roto, puesto que deja una puerta abierta para regresar al sistema anterior con modificaciones que se adapten a esta jurisprudencia.

Por esta razón, siguen vigentes todavía para las personas jurídicas la cuota fija en el orden civil en primera instancia que son de 100 euros en el proceso monitorio, 150 euros en el juicio verbal y 300 euros en el juicio ordinario. Por lo que no podemos hablar de una supresión total, sino que esta sentencia solo supone un parche que no resuelve las lagunas constitucionales de la regulación de las tasas judiciales.

En este recurso de inconstitucionalidad se impugnaban diversos preceptos de la Ley 10/2012, de 20 de noviembre, pero únicamente se analiza y da respuesta de fondo por el Tribunal Constitucional a los artículos $1,3.1$ y 7 de la citada norma.

En cuanto al artículo 1 solo se pronuncia sobre que la previsión de una tasa judicial no puede ser declarada inconstitucional per se, remitiéndose a sentencias pretéritas del mismo tribunal como la STC 20/2012. En relación con el artículo 3, declara la perdida sobrevenida del objeto por la derogación parcial del Real Decreto-Ley 1/2015 de 27 de febrero.

Respecto al artículo 7, se declara la inconstitucionalidad y nulidad de las cuantías de las tasas fijadas tanto para el acceso a la jurisdicción como para la interposición de recursos al considerar que las cuantías son desproporcionadas y vulneran el derecho a la tutela judicial efectiva de los ciudadanos reconocido en el art. 24.1 CE. En este sentido el Tribunal Constitucional señala que: "En definitiva, no se aprecia razón y justificación alguna que acredite que se haya tenido en cuenta que las cuantías establecidas por el art. 7 de la Ley 10/2012, para la interposición de recursos, se adecuen a una capacidad económica que no exceda de la que pueda poseer una persona jurídica; razón por la que esas tasas resultan contrarias al art. 24.1 CE”. 
Una de las problemáticas más importantes de esta sentencia gira en torno a la devolución de la tasa y los efectos de su nulidad. Pues bien, el constitucional considera que la declaración de nulidad sólo producirá efectos a futuro, aplicando la doctrina prospectiva y por lo tanto establece que las tasas ya pagadas en principio no serán devueltas.

Sin embargo, abre una vía de recuperación del importe de la tasa cuando el procedimiento no está finalizado siempre que la persona obligada al pago la hubiera impugnado por impedirle el acceso a la jurisdicción o al recurso en su caso. En palabras de CAAMAÑO ANIDO, M. (2016) Catedrático de Derecho Tributario: "La declaración de inconstitucionalidad es eficaz en relación con nuevos supuestos o en relación a los procedimientos administrativos y procesos judiciales en relación con los cuales todavía no haya recaído resolución o sentencia firme, dejando el camino abierto a solicitudes de rectificación y consiguiente devolución de ingresos indebidos ${ }^{\prime 6}$

Esto obliga al justiciable a acudir a la vía administrativa que tiene un plazo de 6 meses para resolver la reclamación por ingreso indebido y en caso de resolución desfavorable tendría que interponer reclamación económica administrativa ante el correspondiente Tribunal Económico Administrativo Regional. Si nuevamente fuese desfavorable, se promoverían los correspondientes recursos contencioso-administrativos ante los Tribunales Superiores de Justicia.

En efecto, el vía crucis administrativo y judicial por la que tiene que pasar el reclamante es excesivamente oneroso después de haber pagado un tributo declarado nulo por el Tribunal Constitucional. Sin hablar de los que ya no tienen ningún recurso para recuperar estas cantidades injustamente detraídas, puesto que la justificación que da este órgano es que no puede considerarse que los que han pagado la tasa se les ha impetrado la potestad jurisdiccional que solicitaban, es decir, que no se ha producido una lesión del derecho fundamental, que deba repararse mediante la devolución del importe pagado.

En este sentido, es relevante hacer referencia a la interpretación de la sentencia que hace la Dirección General de Tributos en su consulta V8572-16 en la que descarta la devolución de las tasas judiciales en los procedimientos finalizados por resolución firme, como en los procedimientos no finalizados en los que el abono de la tasa no fue acompañado de la impugnación a la que se refiere la sentencia. Sin embargo, exime a los obligados tributarios en aquellos casos en que devengada la tasa este haya sido requerido, pero no haya procedido al abono de la misma.

Esta es una más de las contradicciones en las que incurre el TC en su jurisprudencia sobre las tasas, ya que aquí hace una valoración indiscriminada de que todos los que han pagado la tasa no han sido vulnerados en su derecho a la tutela judicial efectiva por el mero hecho de abonar el pago de la misma. Esto, a mi juicio, es un subterfugio jurisprudencial sin base jurídica cuya justificación reside en la merma que supondría en las cuentas públicas la devolución de las cantidades indebidamente cobradas.

\begin{tabular}{lccc}
\hline 6 & CAAMANO & ANIDO: & http://www.expansion.com/juridico/actualidad- \\
tendencias/2016/09/29/57ecf3d9468aeb3d198b4600.html &
\end{tabular} 


\section{BIBLIOGRAFÍA}

CAAMAÑO ANIDO: $\quad$ http://www.expansion.com/juridico/actualidadtendencias/2016/09/29/57ecf3d9468aeb3d198b4600.html

GARBERÍ LLOBREGAT: El derecho a la tutela judicial efectiva en la jurisprudencia del tribunal constitucional, Bosch, Barcelona 2008.

PICÓ Y JUNOY: Las garantías constitucionales del proceso, Bosch Procesal, Barcelona 2012.

RODRIGUEZ CARBAJO: "Las tasas judiciales: retorno a 1959", Actualidad administrativa, $\mathrm{N}^{\mathrm{o}}$ 19-20, 2012. 